J. Dairy Sci. 92:2915-2921

doi:10.3168/jds.2008-1647

(c) American Dairy Science Association, 2009.

\title{
Economic weights for genetic improvement of lactation persistency and milk yield
}

\author{
K. Togashi ${ }^{* 1}$ and C. Y. Lin† \\ *National Agricultural Research Centre in Hokkaido Region, Hitsujigaoka 1, Toyohiraku, Sapporo, Japan 0628555 \\ †Dairy and Swine Research and Development Centre, Agriculture and Agri-Food Canada, 2000 College St., PO Box 90-STN Lennoxville, \\ Sherbrooke, Quebec, Canada J1M 1 Z3
}

\section{ABSTRACT}

This study aimed to establish a criterion for measuring the relative weight of lactation persistency (the ratio of yield at $280 \mathrm{~d}$ in milk to peak yield) in restricted selection index for the improvement of net merit comprising 3 -parity total yield and total lactation persistency. The restricted selection index was compared with selection based on first-lactation total milk yield $\left(\mathrm{I}_{1}\right)$, the firsttwo-lactation total yield $\left(\mathrm{I}_{2}\right)$, and first-three-lactation total yield $\left(\mathrm{I}_{3}\right)$. Results show that genetic response in net merit due to selection on restricted selection index could be greater than, equal to, or less than that due to the unrestricted index depending upon the relative weight of lactation persistency and the restriction level imposed. When the relative weight of total lactation persistency is equal to the criterion, the restricted selection index is equal to the selection method compared $\left(\mathrm{I}_{1}, \mathrm{I}_{2}\right.$, or $\left.\mathrm{I}_{3}\right)$. The restricted selection index yielded a greater response when the relative weight of total lactation persistency was above the criterion, but a lower response when it was below the criterion. The criterion varied depending upon the restriction level $(c)$ imposed and the selection criteria compared. A curvilinear relationship (concave curve) exists between the criterion and the restricted level. The criterion increases as the restriction level deviates in either direction from 1.5. Without prior information of the economic weight of lactation persistency, the imposition of the restriction level of 1.5 on lactation persistency would maximize change in net merit. The procedure presented allows for simultaneous modification of multi-parity lactation curves.

Key words: criterion, restricted index, total milk yield, total lactation persistency

Received August 22, 2008.

Accepted February 7, 2009.

${ }^{1}$ Corresponding author: tkenji@naro.affrc.go.jp

\section{INTRODUCTION}

Milk yield and lactation persistency are two economically important traits in dairy production. Lactation persistency refers to the rate of decline in daily yield after the peak within lactation. The lower the rate of decline after the peak, the higher the lactation persistency and the more desirable it is economically. Various measures of lactation persistency have been reported in the literature (see review by Gengler, 1996; Swalve and Gengler, 1999). A cow with a higher lactation persistency makes better use of inexpensive forage (Solkner and Fuchs, 1987), suffers less stress from high peak yield (Zimmermann and Sommer, 1973; Muir et al., 2004; Weller et al., 2006), is more resistant to disease (Jakobsen, 2002; Harder et al., 2006), shows an increased conception rate (Bar-Anan and Ron, 1985) and probability of pregnancy (De Vries, 2006), and is more profitable (Dekkers et al., 1998). Lactation persistency received a greater emphasis on organic dairy farms than on conventional farms (Rozzi et al., 2007).

Currently, most selection indices treat protein yield as the main trait of interest (VanRaden, 2004; Miglior et al., 2005) without consideration of increased lactation persistency. One of the main obstacles to incorporate lactation persistency into a selection scheme is the determination of the economic weights for lactation persistency, which requires the expensive collection of a comprehensive data set and involves the difficulty of objectively assessing the economic effects of lactation persistency components such as stress and disease resistance. For these reasons, there is a lack of reports about the economic values of lactation persistency relative to milk production and other economic traits. However, an effective breeding program designed to maximize milk yield subject to the restriction on lactation persistency requires predetermination of the level of restriction to be imposed and the relative weights between milk yield and lactation persistency. The purpose of this study was to determine the restriction level on total lactation persistency of the first 3 parities for the construction of a restricted index to maximize the genetic response 
in net merit comprising 3-parity total yield and total lactation persistency.

\section{MATERIALS AND METHODS}

\section{Genetic Parameter Estimates}

The genetic parameter estimates of the first 3 lactations used for this study were based on Togashi et al. (2008) who used a 3-lactation random regression (RR) test-day (TD) model with a cubic Legendre polynomial (LP) to analyze TD data of Japanese Holstein cows. The number of covariates fitted for the cubic LP is $\mathrm{k}=$ 4. The 3-parity RR TD model fitted with the cubic LP produced a $(12 \times 1)$ vector $(\boldsymbol{\alpha})$ of the additive genetic $\mathrm{RR}$ coefficients of a particular animal (3 lactations $\times \mathrm{k}$ $=12)$ with a $(12 \times 12)$ additive genetic $\mathrm{RR}$ covariance matrix $\mathbf{K}$ of the first 3 lactations:

$$
\boldsymbol{\alpha}=\left[\begin{array}{l}
\boldsymbol{\alpha}_{(1)} \\
\boldsymbol{\alpha}_{(2)} \\
\boldsymbol{\alpha}_{(3)}
\end{array}\right],
$$

with the variance of $\boldsymbol{\alpha}$ being

$$
\operatorname{Var}(\boldsymbol{\alpha})=\mathbf{K}=\left[\begin{array}{lll}
\mathbf{K}_{11} & \mathbf{K}_{12} & \mathbf{K}_{13} \\
\mathbf{K}_{21} & \mathbf{K}_{22} & \mathbf{K}_{23} \\
\mathbf{K}_{31} & \mathbf{K}_{32} & \mathbf{K}_{33}
\end{array}\right],
$$

where $\boldsymbol{\alpha}_{(i)}$ is a $(\mathrm{k} \times 1)$ vector of the additive genetic $\mathrm{RR}$ coefficients that apply to individual animals of the $i$ th lactation. Let $\boldsymbol{\Phi}_{(i)}$ be the $(301 \times \mathrm{k})$ LP coefficient matrix of the $i$ th lactation, where $\boldsymbol{\Phi}_{(1)}=\Phi_{(2)}=\Phi_{(3)}$. The diagonal blocks $\left(\mathbf{K}_{11}, \mathbf{K}_{22}\right.$, and $\left.\mathbf{K}_{33}\right)$ of the matrix $\mathbf{K}$ are the additive genetic $\mathrm{RR}$ coefficient covariance matrices within parity, and the off-diagonal blocks $\left(\mathbf{K}_{\mathrm{ij}}\right)$ are the additive genetic $\mathrm{RR}$ coefficient covariance matrices between parities $i$ and $j$. The EBV of the daily yields from DIM 5 to 305 of the ith lactation are $\boldsymbol{\Phi}_{(i)} \mathbf{\alpha}_{(i)}$ and the EBV for a particular animal of the $i$ th lactation is $\mathbf{1}^{\prime} \boldsymbol{\Phi}_{(i)} \boldsymbol{\alpha}_{(i)}$, where $\mathbf{1}$ is a summing vector. Throughout the text, subscript $(i)$ refers to the number of lactations.

\section{Selection Criteria Compared}

Lactation persistency was defined as the ratio of yield at DIM 280 to peak yield $\left(\right.$ yield $_{280} /$ yield $\left._{\text {peak }}\right)$. Days to reach peak yield were 45,40 , and 36 for the first 3 parities, respectively (Togashi et al., 2008). Total lactation persistency is the sum of lactation persistency of the first 3 lactations and similarly, total yield is the sum of 305-d milk of the first 3 lactations. This study aims to develop the weight of total lactation persistency relative to total yield for deciding if genetic response due to a restricted index would be more than, equal to, or less than that due to the unrestricted indexes. Three unrestricted indexes and a restricted index compared are described as follows: 1) selection based on the firstparity milk $\left.\operatorname{EBV}\left(\mathbf{I}_{1}\right) ; 2\right)$ selection based on the first 2-parity total milk $\left.\operatorname{EBV}\left(\mathbf{I}_{\mathbf{2}}\right) ; 3\right)$ selection based on the first 3-parity total milk EBV $\left(\mathbf{I}_{3}\right)$; and 4) selection based on all eigenvectors of $\mathbf{K}$ with restriction on lactation persistency $\left(\mathbf{I}^{*}\right)$.

Eigen Index Using All Eigenvectors of $K$ with Restriction on Lactation Persistency. The restricted eigen index $\left(I^{*}\right)$ using all eigenvectors of $\mathbf{K}$ was designed to maximize the total milk subject to the restriction on lactation persistency of each of the 3 lactations. The genetic value for a particular animal of the first 3 lactation total yield is $\mathrm{H}=g_{(1)}+g_{(2)}+g_{(3)}$, where $g_{(i)}$ is the genetic value for a particular animal of the $i$ th lactation milk. In matrix notation, $\mathrm{H}=\mathbf{1}^{\prime} \mathbf{F} \alpha$, where the matrix $\mathbf{F}$ of order $(903 \times 3 \mathrm{k})$ is:

$$
\mathbf{F}=\left[\begin{array}{ccc}
\boldsymbol{\Phi}_{(1)} & \mathbf{0} & \mathbf{0} \\
\mathbf{0} & \boldsymbol{\Phi}_{(2)} & \mathbf{0} \\
\mathbf{0} & \mathbf{0} & \boldsymbol{\Phi}_{(3)}
\end{array}\right]
$$

The following restrictions were imposed on lactation persistency of each of the 3 lactations:

$$
\frac{\Delta G_{280(1)}}{\Delta G_{\text {peak }(1)}}=\frac{\Delta G_{280(2)}}{\Delta G_{\text {peak }(2)}}=\frac{\Delta G_{280(3)}}{\Delta G_{\text {peak }(3)}}=c,
$$

where $\Delta G_{280(i)}$ and $\Delta G_{\text {peak }(i)}$ are the genetic responses at 280 DIM and peak DIM of the $i$ th lactation $(i=1$, 2 , or 3), respectively. The ratio of $\Delta G_{280(i)}$ to $\Delta G_{p e a k(i)}$ is the genetic response in lactation persistency of the $i$ th lactation. Therefore, the level of restriction $(c)$ defined above is expected to be the same as the genetic response in lactation persistency due to the restricted index, but this is not the case for the unrestricted indexes. Different degrees of restrictions $(c)$ were imposed to construct various restricted indexes with $c$ ranging from 1.4 to 2.1 (Table 1). This study imposed the same restriction on lactation persistency of the 3 lactations [i.e., $c_{(1)}=c_{(2)}$ $\left.=c_{(3)}=c\right]$ although different restrictions could be applied among lactations. Note that lactation persistency before and after selection remains unchanged when $c=$ 1 , increases when $c>1$, and deteriorates when $c<1$. 
Table 1. Genetic response in total milk and total persistency due to the restricted and the unrestricted selection indexes

\begin{tabular}{|c|c|c|c|c|c|c|c|c|c|c|c|}
\hline Genetic response & \multicolumn{3}{|c|}{ Unrestricted indexes } & \multicolumn{8}{|c|}{ Restricted index $\left(\mathrm{I}^{*}\right)$} \\
\hline \multicolumn{12}{|l|}{ Lactation milk } \\
\hline First parity & 848.2 & 840.2 & 836.5 & 821.2 & 818.9 & 807.2 & 789.3 & 768.0 & 745.1 & 722.0 & 699.5 \\
\hline Second parity & $1,234.4$ & $1,262.3$ & $1,247.2$ & $1,194.3$ & $1,205.1$ & $1,201.1$ & $1,186.8$ & $1,166.1$ & $1,141.6$ & $1,115.6$ & $1,089.4$ \\
\hline Third parity & $1,140.1$ & $1,136.0$ & $1,184.0$ & $1,177.5$ & $1,175.5$ & $1,161.4$ & $1,139.4$ & $1,112.9$ & $1,084.4$ & $1,055.7$ & $1,027.7$ \\
\hline \multicolumn{12}{|l|}{ First parity } \\
\hline$\Delta \mathrm{G}_{280(1)}$ & 3.112 & 3.134 & 3.125 & 3.067 & 3.141 & 3.171 & 3.167 & 3.141 & 3.101 & 3.053 & 3.000 \\
\hline$\Delta \mathrm{G}_{\text {peak }(1)}$ & 2.273 & 2.224 & 2.204 & 2.191 & 2.094 & 1.982 & 1.863 & 1.745 & 1.632 & 1.526 & 1.429 \\
\hline$\Delta \mathrm{G}_{280(1)} / \Delta \mathrm{G}_{\text {peak }(1)}$ & 1.369 & 1.409 & 1.418 & 1.400 & 1.500 & 1.600 & 1.700 & 1.800 & 1.900 & 2.000 & 2.100 \\
\hline \multicolumn{12}{|l|}{ Second parity } \\
\hline$\Delta \mathrm{G}_{280(2)}$ & 4.199 & 4.298 & 4.357 & 4.482 & 4.615 & 4.685 & 4.707 & 4.695 & 4.660 & 4.612 & 4.556 \\
\hline$\Delta \mathrm{G}_{p e a k(2)}$ & 3.598 & 3.694 & 3.565 & 3.201 & 3.077 & 2.928 & 2.769 & 2.608 & 2.453 & 2.306 & 2.170 \\
\hline \multicolumn{12}{|l|}{ Total persistency } \\
\hline$\Delta \mathrm{G}_{280} / \Delta \mathrm{G}_{\text {peak }}$ & 3.675 & 3.682 & 3.777 & 4.200 & 4.500 & 4.800 & 5.100 & 5.400 & 5.700 & 6.000 & 6.300 \\
\hline
\end{tabular}

${ }^{1} c=$ the level of restriction imposed on persistency for the construction of $\mathrm{I}^{*}$.

${ }^{2}$ Persistency $=\Delta \mathrm{G}_{280} / \Delta \mathrm{G}_{\text {peak }}$, where $\Delta \mathrm{G}_{280}$ and $\Delta \mathrm{G}_{\text {peak }}$ are genetic responses in yield at 280 DIM and peak DIM, respectively.

The restricted eigen index $\left(\mathbf{I}^{*}\right)$ is $\mathrm{I}^{*}=\mathrm{b}^{* \prime} \mathbf{E}^{\prime} \alpha$, where $\mathrm{b}^{*}$ is the $(3 \mathrm{k} \times 1)$ vector containing the index coefficients, and $\mathbf{E}$ is the $(3 \mathrm{k} \times 3 \mathrm{k})$ matrix containing the normalized eigenvectors $\left(e_{i}\right)$ of $\mathbf{K}$ corresponding to the eigenvalues $\lambda_{i}$ that are sorted in descending order; that is, $\mathbf{E}=\left[e_{1}, e_{2}, \ldots, e_{3 k}\right]$. The restriction on lactation persistency of each of the 3 lactations is $\Delta G_{280(i)}=$ $c \Delta G_{\text {peak }(i)}(i=1,2$, or 3$)$, which can be expressed as $\boldsymbol{\Phi}_{280(i)} \mathbf{K E} b^{*}=c \boldsymbol{\Phi}_{\text {peak }(i)} \mathbf{K E} b^{*}(i=1,2$, or 3$)$, where the vectors $\boldsymbol{\Phi}_{280(i)}$ and $\boldsymbol{\Phi}_{\text {peak }(i)}$ contain the rows of the LP coefficient matrix $\left(\boldsymbol{\Phi}_{(i)}\right)$ corresponding to 280 DIM and peak DIM of the ith lactation. Consequently, simultaneous restriction on lactation persistency of the first 3 lactations is $\mathbf{\Psi K E} b^{*}=\mathbf{0}$, where $\boldsymbol{\Psi}$ of order $(3 \times 3 \mathrm{k})$ is

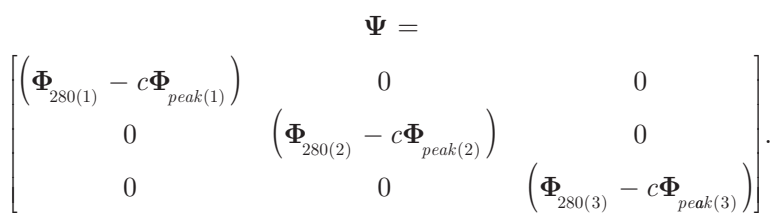

Detailed procedures for constructing various eigen indices were given in Togashi and Lin (2006, 2007). Briefly, the Lagrange multipliers function takes the following form:

$$
\begin{aligned}
f & =\operatorname{Var}\left(\mathbf{I}^{*}-\mathbf{H}\right)+\eta^{\prime}\left(\mathbf{\Psi} \mathbf{K E} b^{*}\right) \\
& =\left(b^{* \prime} \mathbf{E}^{\prime} \alpha-\mathbf{1}^{\prime} \mathbf{F} \alpha\right)^{2}+\eta^{\prime}\left(\mathbf{\Psi} \mathbf{K} \mathbf{E} b^{*}\right) \\
& =\left(b^{* \prime} \mathbf{D} b^{*}-2 b^{* \prime} \mathbf{E}^{\prime} \mathbf{K} \mathbf{F}^{\prime} \mathbf{1}+\mathbf{1}^{\prime} \mathbf{G} \mathbf{1}+\eta^{\prime}\left(\mathbf{\Psi} \mathbf{K E} b^{*}\right),\right.
\end{aligned}
$$

where $\mathbf{D}$ is a $(3 \mathrm{k} \times 3 \mathrm{k})$ diagonal matrix with eigenvalues of $\mathbf{K}$ on the diagonal, $\mathbf{G}$ is a $(903 \times 903)$ genetic covariance matrix of daily yields (from 5 to 305 DIM) among the first 3 lactations, and $\eta$ is a $(3 \times 1)$ vector of Lagrange multipliers. Taking the derivative of the function $f$ with respect to vectors $b^{*}$ and $\eta$ and equating the partial derivatives to zeroes results in the following equations:

$$
\frac{\partial f}{\partial b^{*}}=2 \mathbf{D} b^{*}-2 \mathbf{E}^{\prime} \mathbf{K} \mathbf{F}^{\prime} \mathbf{1}+\mathbf{E}^{\prime} \mathbf{K} \Psi^{\prime} \eta=0
$$

$$
\frac{\partial f}{\partial \eta}=\mathbf{\Psi K E} b^{*}=0
$$

These 2 sets of equations can be written jointly as follows:

$$
\left[\begin{array}{cc}
2 \mathbf{D} & \mathbf{E}^{\prime} \mathbf{K} \boldsymbol{\Psi}^{\prime} \\
\mathbf{\Psi} \mathbf{K E} & 0
\end{array}\right]\left[\begin{array}{l}
b^{*} \\
\eta
\end{array}\right]=\left[\begin{array}{c}
2 \mathbf{E}^{\prime} \mathbf{K} \mathbf{F}^{\prime} \mathbf{1} \\
0
\end{array}\right] .
$$




\section{Determination of Relative Economic Weights}

Let $g_{m}$ and $g_{p}$ be the genetic values of total milk and total lactation persistency, respectively, and $w_{m}$ and $w_{p}$ are the relative weights between $g_{m}$ and $g_{p}$. Let $\Delta \mathrm{G}_{\mathrm{m}}$ and $\Delta \mathrm{G}_{\mathrm{p}}$ be the genetic responses in total milk and total lactation persistency due to the unrestricted selection indexes $\mathrm{I}_{1}, \mathrm{I}_{2}$, or $\mathrm{I}_{3}$. Similarly, let $\Delta \mathrm{G}_{\mathrm{m}}{ }^{*}$ and $\Delta \mathrm{G}_{\mathrm{p}}{ }^{*}$ be the genetic responses in total milk and total lactation persistency due to the restricted eigen index $I^{*}$ with restriction on total lactation persistency.

The total genetic response in net merit $(\Delta \mathbf{T})$ is defined as the linear combination of genetic responses in total milk and total lactation persistency weighted by their relative weights. The total genetic response due to the unrestricted index $\mathrm{I}_{1}, \mathrm{I}_{2}$, or $\mathrm{I}_{3}$ takes a general form of

$$
\Delta t=w_{m} \Delta \mathrm{G}_{\mathrm{m}}+w_{p} \Delta \mathrm{G}_{\mathrm{p}}
$$

Likewise, the total genetic response due to the restricted eigen index $I^{*}$ is

$$
\Delta \mathrm{T}^{*}=w_{m} \Delta \mathrm{G}_{\mathrm{m}}^{*}+w_{p} \Delta \mathrm{G}_{\mathrm{p}}^{*} .
$$

For simplicity, let $w_{m}=1$. However, $w_{m}$ can be set to any constant without affecting the relative weights between $w_{m}$ and $w_{p}$. When I and $\mathrm{I}^{*}$ are equally efficient, meaning that $\Delta t=\Delta \mathrm{T}^{*}$, it follows that

$$
w_{m} \Delta \mathrm{G}_{\mathrm{m}}+w_{p} \Delta \mathrm{G}_{\mathrm{p}}=w_{m} \Delta \mathrm{G}_{\mathrm{m}}{ }^{*}+w_{p} \Delta \mathrm{G}_{\mathrm{p}}{ }^{*} .
$$

Substituting $w_{m}=1$ and rearranging this equation leads to $w_{p}=\left(\Delta \mathrm{G}_{\mathrm{m}}-\Delta \mathrm{G}_{\mathrm{m}}{ }^{*}\right) /\left(\Delta \mathrm{G}_{\mathrm{p}}{ }^{*}-\Delta \mathrm{G}_{\mathrm{p}}\right)$. Let $\left(\Delta \mathrm{G}_{\mathrm{m}}-\Delta \mathrm{G}_{\mathrm{m}}{ }^{*}\right) /\left(\Delta \mathrm{G}_{\mathrm{p}}{ }^{*}-\Delta \mathrm{G}_{\mathrm{p}}\right)$ be equal to $\delta$. Therefore, selection methods I and $\mathrm{I}^{*}$ are equivalent $(\Delta t=$ $\Delta \mathrm{T}^{*}$ ) only if $w_{p}=\delta$ (i.e., $w_{m}: w_{p}=1: \delta$ ). When selection method I is more efficient than I* (i.e., $\Delta t>\Delta \mathrm{T}^{*}$ ), this means that $w_{m} \Delta \mathrm{G}_{\mathrm{m}}+w_{p} \Delta \mathrm{G}_{\mathrm{p}}>w_{m} \Delta \mathrm{G}_{\mathrm{m}}{ }^{*}+w_{p} \Delta \mathrm{G}_{\mathrm{p}}{ }^{*}$. This inequality is satisfied only if $w_{p}<\delta$. When selection method $\mathrm{I}$ is less efficient than $\mathrm{I}^{*}$ (i.e., $\Delta t<\Delta \mathrm{T}^{*}$ ), this indicates that $w_{m} \Delta \mathrm{G}_{\mathrm{m}}+w_{p} \Delta \mathrm{G}_{\mathrm{p}}<w_{m} \Delta \mathrm{G}_{\mathrm{m}}{ }^{*}+$ $w_{p} \Delta \mathrm{G}_{\mathrm{p}}{ }^{*}$, which leads to $w_{p}>\delta$. Thus, the developed parameter $\delta$ provides a measure for determining if it is justified to apply the restricted index I* instead of the unrestricted index I.

\section{RESULTS AND DISCUSSION}

This study relates to random regression prediction of $305-\mathrm{d}$ yields and to relative economic weights of total yield and total lactation persistency of the first 3 lactations. The random regression procedure permits the estimation of the genetic responses in yield at DIM 280 and peak DIM (i.e., $\Delta \mathrm{G}_{280}$ and $\Delta G_{\text {peak }}$ ), which are used to determine genetic progress in lactation persistency defined as the ratio $\Delta \mathrm{G}_{280}: \Delta G_{\text {peak }}$. The first 3 leading eigenvectors of $\mathbf{K}$ used in this study are related to the level of milk yield, linear increase, and the concave curve, respectively (Togashi et al., 2008). Table 1 shows the genetic responses in the first-three-lactation total milk $\left(\Delta \mathrm{G}_{\mathrm{m}}{ }^{*}\right.$ or $\left.\Delta \mathrm{G}_{\mathrm{m}}\right)$ and total lactation persistency $\left(\Delta \mathrm{G}_{\mathrm{p}}{ }^{*}\right.$ or $\left.\Delta \mathrm{G}_{\mathrm{p}}\right)$ due to the restricted index $\left(\mathrm{I}^{*}\right)$ or the unrestricted indexes: the first-lactation milk $\operatorname{EBV}\left(\mathrm{I}_{1}\right)$, the first 2-lactation milk EBV $\left(\mathrm{I}_{2}\right)$, and the first 3-lactation milk EBV $\left(\mathrm{I}_{3}\right)$, respectively. Also listed in Table 1 are the genetic responses at DIM 280 (i.e., $\Delta \mathrm{G}_{280(i)}$ ) and peak DIM (i.e., $\left.\Delta G_{\text {peak }(i)}\right)$ of each parity $(\mathrm{i}=1,2$, $3)$. Table 1 shows that the genetic responses in lactation persistency $\left(\Delta \mathrm{G}_{280(i)}: \Delta G_{\text {peak }(i)}\right)$ due to the restricted index I* are the same as the size of restrictions $(c)$ imposed, confirming that the restricted index satisfies the imposed restrictions.

The restricted index I* produced a greater response in total lactation persistency $\left(\Delta \mathrm{G}_{\mathrm{p}}{ }^{*}>\Delta \mathrm{G}_{\mathrm{p}}\right)$, but a smaller response in total milk $\left(\Delta \mathrm{G}_{\mathrm{m}}{ }^{*}<\Delta \mathrm{G}_{\mathrm{m}}\right)$ than conventional selection based on milk $\left(\mathrm{I}_{1}, \mathrm{I}_{2}\right.$, or $\left.\mathrm{I}_{3}\right)$. Selection based on the 3-lactation total milk $\operatorname{EBV}\left(\mathrm{I}_{3}\right)$ produced greater responses in both total milk $(3,267.7$ $\mathrm{kg}$ ) and total lactation persistency (1.237) compared with selection based on $\mathrm{I}_{1}(3,222.7 \mathrm{~kg}$ and 1.206) and $\mathrm{I}_{2}(3,238.5 \mathrm{~kg}$ and 1.203). The genetic response in total lactation persistency due to selection on $\mathrm{I}^{*}$ is identical to the level of restrictions $(c)$ as expected. The genetic response in total milk is inversely related to the level of restriction imposed (Table 1). This nonlinear relationship occurs because the level of restriction is placed on lactation persistency, which was defined as a ratio in this study. Genetic response in total milk $(3,199.4 \mathrm{~kg})$ due to the restricted index is optimized when the level of restriction is $c=1.6$.

In this study, the weighting factor of total milk was set to unity $\left(w_{m}=1\right)$ to derive the parameter $\delta=\left(\Delta \mathrm{G}_{\mathrm{m}}\right.$ $\left.-\Delta \mathrm{G}_{\mathrm{m}}{ }^{*}\right) /\left(\Delta \mathrm{G}_{\mathrm{p}}{ }^{*}-\Delta \mathrm{G}_{\mathrm{p}}\right)$. However, $w_{m}$ may be set to any constant without affecting the relative weights between total milk and total lactation persistency $\left(w_{m}\right.$ : $w_{p}$ ). Various quantities of $\delta$ for different combinations of the level of restrictions and the unrestricted indexes are given in Table 2 . The criterion $\delta$ determines if selection on total milk subject to restriction on total lactation persistency is more, equivalent to, or less efficient than conventional selection based on milk yields $\left(\mathrm{I}_{1}, \mathrm{I}_{2}, \mathrm{I}_{3}\right)$ without restriction on lactation persistency. When the relative economic weight of total lactation persistency $\left(w_{p}\right)$ is equal to the criterion $\delta$ (i.e., $w_{p}=\delta$ ), selection on $I^{*}$ is equivalent to the specific selection criterion compared $\left(\mathrm{I}_{1}, \mathrm{I}_{2}\right.$, or $\left.\mathrm{I}_{3}\right)$. When $w_{p}$ is greater than the criterion $\delta\left(w_{p}>\delta\right)$, the index I* is more effective than 
Table 2. The parameter $\delta$ of the relative economic weight of total persistency for determining the effectiveness of the restricted index ( $\mathrm{I}^{*}$ ) compared with selection based on first-parity, first-2-parity, and first-3-parity milk, respectively ${ }^{1}$

\begin{tabular}{lcccccccc}
\hline & \multicolumn{7}{c}{ Level of restrictions $(c)$ on persistency in the construction of $I^{*}$} \\
\cline { 2 - 8 } Index I* compared with: & 1.4 & 1.5 & 1.6 & 1.7 & 1.8 & 1.9 & 2.0 & 2.1 \\
\hline Selection on first-parity milk $\left(\mathrm{I}_{1}\right)$ & 56.3 & 28.2 & 47.1 & 75.2 & 101.9 & 124.2 & 141.7 & 154.7 \\
Selection on first-2-parity milk $\left(\mathrm{I}_{2}\right)$ & 87.7 & 47.8 & 61.6 & 86.7 & 111.5 & 132.5 & 148.9 & 161.2 \\
Selection on first-3-parity milk $\left(\mathrm{I}_{3}\right)$ & 176.7 & 94.6 & 95.9 & 115.0 & 136.1 & 154.2 & 168.4 & 178.8 \\
\hline
\end{tabular}

${ }^{1}$ Economic weight of total milk was set to be unity in deriving the parameter $\delta$, where $\delta=\left(\Delta \mathrm{G}_{\mathrm{m}}-\Delta \mathrm{G}_{\mathrm{m}}{ }^{*}\right) /\left(\Delta \mathrm{G}_{\mathrm{p}}{ }^{*}-\Delta \mathrm{G}_{\mathrm{p}}\right) ; \Delta \mathrm{G}_{\mathrm{m}}=$ genetic gain in total milk due to $\mathrm{I}_{1}, \mathrm{I}_{2}$, or $\mathrm{I}_{3} ; \Delta \mathrm{G}_{\mathrm{m}}{ }^{*}=$ genetic gain in total milk due to $\mathrm{I}^{*} ; \Delta \mathrm{G}_{\mathrm{p}}{ }^{*}=$ genetic gain in total persistency due to $\mathrm{I}^{*} ; \Delta \mathrm{G}_{\mathrm{p}}=$ genetic gain in total persistency due to $\mathrm{I}_{1}, \mathrm{I}_{2}$, or $\mathrm{I}_{3}$.

the selection criterion compared, and when $w_{p}$ is smaller than the criterion $\delta\left(w_{p}<\delta\right)$, the index I* becomes less effective. For example, if comparison is made between criteria $I_{1}$ and $I^{*}$ where the index $I^{*}$ is subject to the restriction of 1.5 on total lactation persistency $(c=$ 1.5), the criterion $\delta$ is $(3,222.7-3,199.4) /(4.5-3.675)$ $=28.2$ (Table 2). When $w_{p}=28.2$, the index $\mathrm{I}^{*}$ and $\mathrm{I}_{1}$ are equally effective; when $w_{p}>28.2$, the index $\mathrm{I}^{*}$ is more effective than $\mathrm{I}_{1}$; and when $w_{p}<28.2$, the index $I^{*}$ is less effective than $I_{1}$.

Table 2 shows that generally, the criterion $\delta$ increases with increasing level of restrictions $(c)$. This is because the imposition of severe restriction on total lactation persistency would reduce the genetic gain in total milk so that the relative economic weight of total lactation persistency $\left(w_{p}\right)$ must increase sufficiently to compensate for the genetic loss in total milk due to the restriction imposed.

Different measures of lactation persistency are reported in the literature (e.g., Swalve and Gengler, 1999; Jakobsen et al., 2002). Given the same set of selection criteria studied, the criterion value $\delta$ would vary depending upon the measure of lactation persistency defined. However, the procedure developed in this study remains applicable to derive the criterion value $\delta$ for determining the relative importance between lactation milk and lactation persistency for pairwise comparison of different selection criteria.

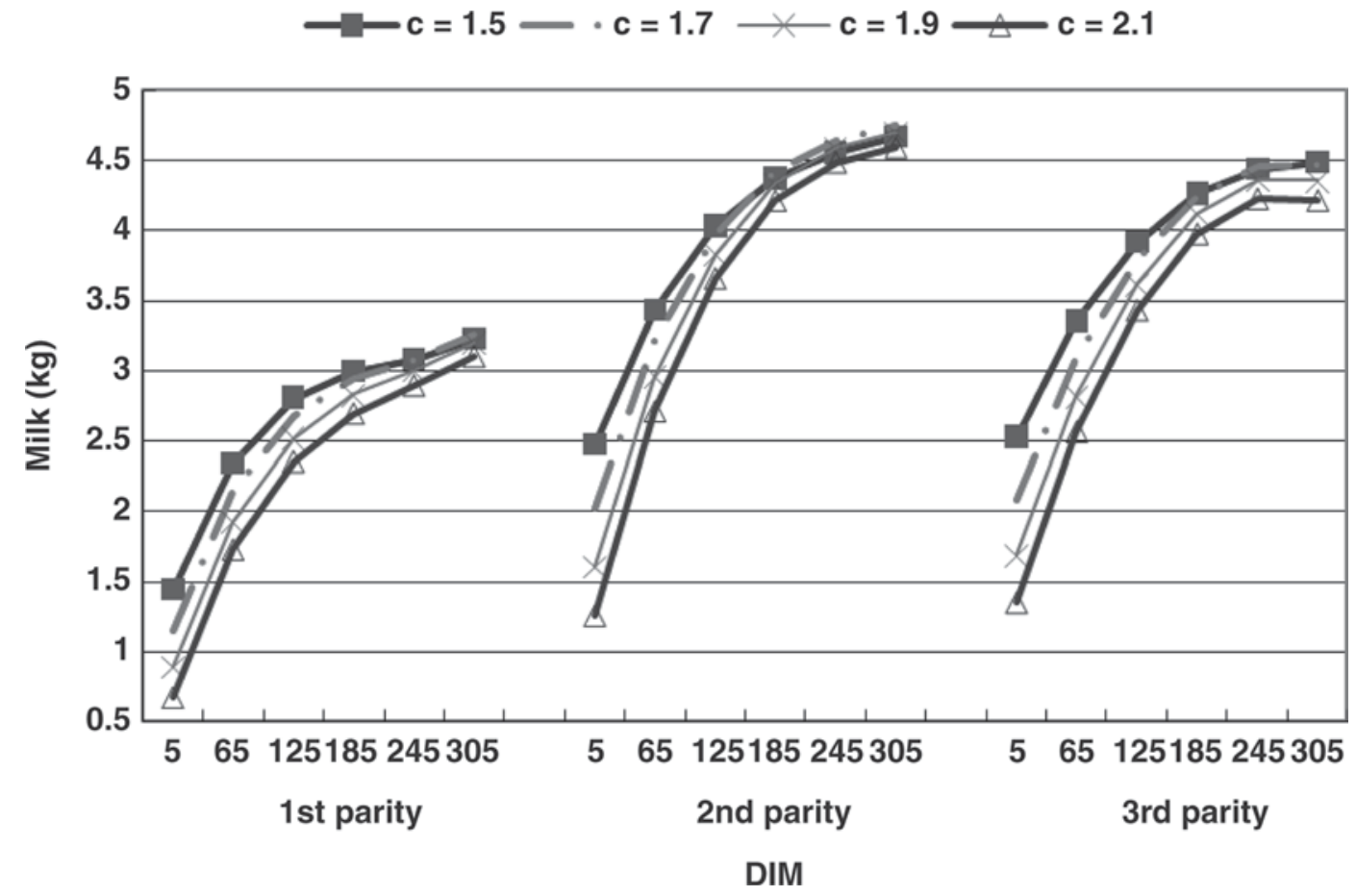

Figure 1. Daily genetic responses in milk of the 3 parities to the restricted index ( $\left.{ }^{*}\right)$ subject to restriction on persistency: $c=\frac{\Delta G_{280(1)}}{\Delta G_{\text {peak }(1)}}=\frac{\Delta G_{280(2)}}{\Delta G_{\text {peak }(2)}}=\frac{\Delta G_{280(3)}}{\Delta G_{\text {peak }(3)}}$. 
Figure 1 shows the patterns of daily genetic response in milk yield to the indexes ( $\left.\mathrm{I}^{*}\right)$ subject to different levels of restriction ( $c=1.5,1.7,1.9$, and 2.1) across the first 3 parities. This figure indicates that regardless of the restriction levels $(c)$, the restricted index $\mathrm{I}^{*}$ based on total milk produced much greater genetic responses in daily yields in the later parities than in the first parity, suggesting that the lactation curves of the first and later parities possess different attributes and thus, need different strategies to manipulate the curves. Because of the restriction imposed, daily genetic responses in the early stage of the 3 lactations were smaller than in the later stage of the corresponding lactations, thus resulting in an improvement of lactation persistency across parity. The procedure presented in this study allows for simultaneous modification of the multi-parity lactation curves. This contrasts with most literature reports that were mainly concerned with modifying the firstlactation curve only (e.g., Danell, 1982; Ferris et al., 1985; Togashi and Lin, 2003). Daily genetic responses for a given lactation decrease consistently as the level of restrictions $(c)$ increases, suggesting that the greater the restrictions imposed on lactation persistency of the 3 lactations, the smaller the daily genetic responses are. Although this study imposed the same restriction level (c) on lactation persistency of the 3 parities, separate levels of restriction could be imposed on different parities.

Figure 2 shows a curvilinear relationship (concave curve) between the criterion $\delta$ and the restriction level $(c)$. The criterion $\delta$ is at a minimum when the level of restriction takes the values of $1.485,1.502$, and 1.540 for $\mathrm{I}_{1}, \mathrm{I}_{2}$, and $\mathrm{I}_{3}$, respectively, with an average of about 1.5 . Regardless of the selection criterion compared $\left(\mathrm{I}_{1}, \mathrm{I}_{2}\right.$, or
$\mathrm{I}_{3}$ ), the criterion $\delta$ increases as the level of restrictions deviates in either direction from the restriction level of 1.5 , which corresponds to the minimum criterion. The restriction level of 1.5 may be considered a yardstick for imposing the restriction on lactation persistency. Extreme deviation from the optimum level would demand extremely severe restriction and extremely high criterion $\delta$ for the restricted index to be as effective as the other selection criteria compared. Without prior information of the relative economic weight of lactation persistency, it is reasonable to design a restricted index to maximize total milk while imposing the restriction level of 1.5 on lactation persistency. Under this condition, the unknown relative economic weight of lactation persistency would be more likely to exceed the minimum criterion so that the restricted index would become more effective than the other selection criteria compared in terms of net merit comprising the multiparity total milk and total lactation persistency.

\section{CONCLUSIONS}

This study demonstrated a procedure to establish a parameter $\delta$ for determining the effectiveness of the restricted index $I^{*}$ compared with selection on firstlactation total yield $\left(\mathrm{I}_{1}\right)$, first-2-lactation total yield $\left(\mathrm{I}_{2}\right)$, or first-3-lactation total yield $\left(\mathrm{I}_{3}\right)$ in terms of genetic response in net merit comprising total milk and total lactation persistency. When the relative weight of total lactation persistency $\left(w_{p}\right)$ is set equal to the parameter $\delta\left(w_{p}=\delta\right)$, the genetic response to selection on $I^{*}$ is identical to the selection method compared $\left(\mathrm{I}_{1}, \mathrm{I}_{2}\right.$, or $\left.\mathrm{I}_{3}\right)$. However, $\mathrm{I}^{*}$ becomes more efficient when $w_{p}$ is greater than $\delta$, but less efficient when $w_{p}$ is less

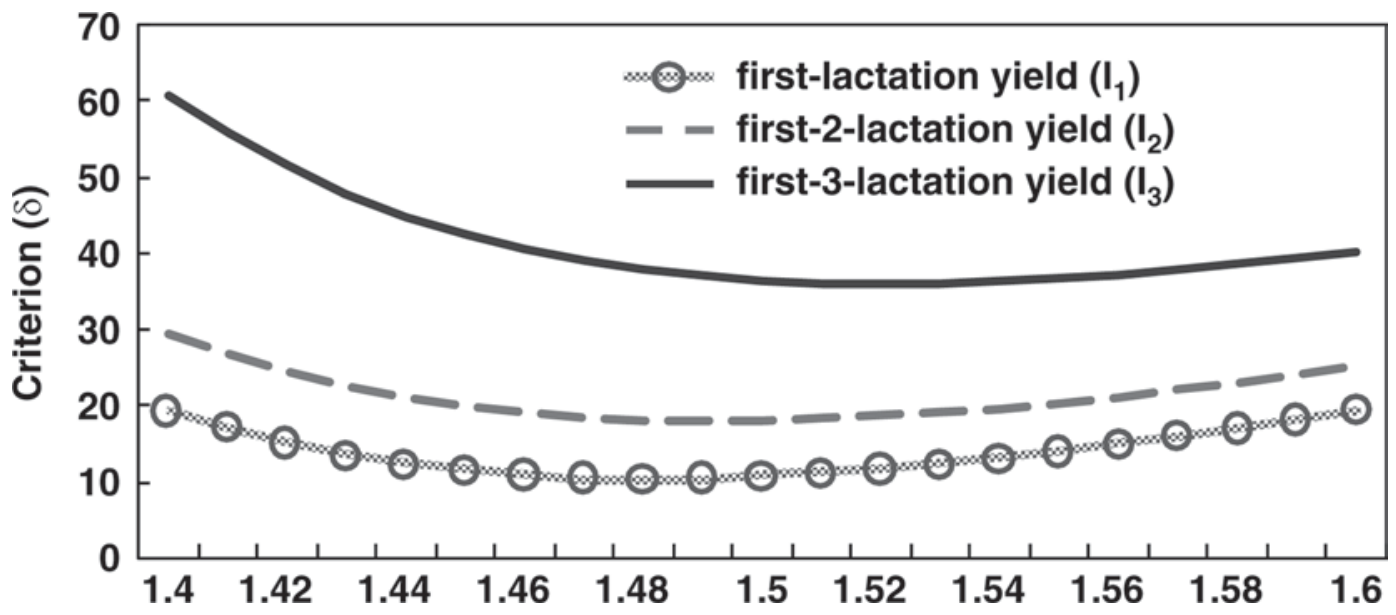

Figure 2. The relationship between the criterion of persistency $(\delta)$ and the level of restriction $(\mathrm{c}): \delta=\left(\Delta \mathrm{G}_{\mathrm{m}}-\Delta \mathrm{G}_{\mathrm{m}}{ }^{*}\right) /\left(\Delta \mathrm{G}_{\mathrm{p}} *-\Delta \mathrm{G}_{\mathrm{p}}\right)$, where $\Delta \mathrm{G}_{\mathrm{m}}$ and $\Delta \mathrm{G}_{\mathrm{p}}$ are the genetic responses in total milk and total lactation persistency due to the unrestricted selection indexes $\mathrm{I}_{1}$, $\mathrm{I}_{2}$, or $\mathrm{I}_{3}$; and $\Delta \mathrm{G}_{\mathrm{m}}{ }^{*}$ and $\Delta \mathrm{G}_{\mathrm{p}}{ }^{*}$ are the genetic responses in total milk and total lactation persistency due to the restricted eigen index I* with restriction on total lactation persistency. 
than $\delta$. The parameter $\delta$ varies depending upon the restriction level imposed and the selection criteria compared. The parameter $\delta$ goes up as the restriction level deviates in either direction from the restriction level of 1.5. Therefore, without prior information of the relative weight of lactation persistency, the imposition of a restriction level of 1.5 on lactation persistency trait of the restricted index $\mathrm{I}^{*}$ would maximize change in net merit. The procedure presented allows for simultaneous modification of multi-parity lactation curves.

\section{REFERENCES}

Bar-Anan, R., and M. Ron. 1985. Association among milk yield, yield persistency, conception, and culling of Israeli Holstein dairy cattle. J. Dairy Sci. 68:382-386.

Danell, B. 1982. Studies on lactation yield and individual test-day yields of Swedish dairy cows. III. Persistency of milk yield and its correlation with lactation yield. Acta Agric. Scand. 32:93-101.

De Vries, A. 2006. Economic value of pregnancy in dairy cattle. J. Dairy Sci. 89:3876-3885.

Dekkers, J. C. M., J. H. Ten Haag, and A. Weersink. 1998. Economic aspects of persistency of lactation in dairy cattle. Livest. Prod. Sci. 53:237-252.

Ferris, T. A., I. L. Mao, and C. R. Anderson. 1985. Selecting for lactation curve and milk yield in dairy cattle. J. Dairy Sci. 68:1438-1448.

Gengler, N. 1996. Persistency of lactation yields: A review. Interbull Bull. 12:87-96.

Harder, B., J. Bennewitz, D. Hinrichs, and E. Kalm. 2006. Genetic parameters for health traits and their relationship to different persistency traits in German Holstein dairy cattle. J. Dairy Sci. 89:3202-3212.

Jakobsen, J. H., P. Madsen, J. Jensen, J. Pedersen, L. G. Christensen, and D. A. Sorensen. 2002. Genetic parameters for milk production and persistency for Danish Holsteins estimated in random regression models using REML. J. Dairy Sci. 85:1607-1616.

Miglior, F., B. L. Muir, and B. J. Van Doormaal. 2005. Selection indices in Holstein cattle of various countries. J. Dairy Sci. 88:1255-1263.

Muir, B. L., J. Fatehi, and L. R. Schaeffer. 2004. Genetic relationships between persistency and reproductive performance in first-lactation Canadian Holsteins. J. Dairy Sci. 87:3029-3037.

Rozzi, P., F. Miglior, and K. J. Hand. 2007. A total merit selection index for Ontario organic dairy farmers. J. Dairy Sci. 90:15841593.

Solkner, J., and W. Fuchs. 1987. A comparison of different measures of persistency with special respect to variation of test-day milk yields. Livest. Prod. Sci. 16:305-319.

Swalve, H. H., and N. Gengler. 1999. Genetics of lactation persistency. Occ. Publ. Br. Soc. Anim. Sci. 24:75-82.

Togashi, K., and C. Y. Lin. 2003. Modifying the lactation curve to improve lactation milk and persistency. J. Dairy Sci. 86:14871493.

Togashi, K., and C. Y. Lin. 2006. Selection for milk production and persistency using eigenvectors of the random regression coefficient matrix. J. Dairy Sci. 89:4866-4873.

Togashi, K., and C. Y. Lin. 2007. Genetic modification of the lactation curve by bending the eigenvectors of the additive genetic random regression coefficient matrix. J. Dairy Sci. 90:5753-5758.

Togashi, K., C. Y. Lin, Y. Atagi, K. Hagiga, J. Sato, and T. Nakanishi. 2008. Genetic characteristics of Japanese Holstein cows based on multiple lactation random regression test-day animal models. Livest. Sci. 114:194-201.

VanRaden, P. M. 2004. Selection on net merit to improve lifetime profit. J. Dairy Sci. 87:3125-3131.

Weller, J. I., E. Ezra, and G. Leitner. 2006. Genetic analysis of persistency in the Israeli Holstein population by the multi-trait animal model. J. Dairy Sci. 89:2738-2746.

Zimmermann, E., and H. Sommer. 1973. Zum Laktationsverlauf von Kuhen in Hochleistung-sherden und dessen Beeinflussung durch nichterbliche Faktoren. Zuchtungskunde 45:75-88. 